\title{
Hand hygiene compliance rates in the United States-a one-year multicenter collaboration using product/volume usage measurement and feedback.
}

\author{
Maryanne McGuckin \\ Jefferson Medical College, School of Population Health \\ Richard Waterman \\ University of Pennsylvania \\ John Govednik \\ Analytic Business Services
}

\section{Follow this and additional works at: https://jdc.jefferson.edu/healthpolicyfaculty \\ Part of the Health Services Research Commons \\ Let us know how access to this document benefits you}

\section{Recommended Citation \\ McGuckin, Maryanne; Waterman, Richard; and Govednik, John, "Hand hygiene compliance rates in the United States--a one-year multicenter collaboration using product/volume usage measurement and feedback." (2009). College of Population Health Faculty Papers. Paper 48. https://jdc.jefferson.edu/healthpolicyfaculty/48}

This Article is brought to you for free and open access by the Jefferson Digital Commons. The Jefferson Digital Commons is a service of Thomas Jefferson University's Center for Teaching and Learning (CTL). The Commons is a showcase for Jefferson books and journals, peer-reviewed scholarly publications, unique historical collections from the University archives, and teaching tools. The Jefferson Digital Commons allows researchers and interested readers anywhere in the world to learn about and keep up to date with Jefferson scholarship. This article has been accepted for inclusion in College of Population Health Faculty Papers by an authorized administrator of the Jefferson Digital Commons. For more information, please contact: JeffersonDigitalCommons@jefferson.edu. 


\author{
As submitted to: \\ American Journal of Medical Quality
}

And later published as:

Hand Hygiene Compliance Rates in U.S. - A One-Year Multicenter Collaborative Using Product/Volume Usage Measurement and Feedback

March 2009 24(3): 205-213

DOI: $10.1177 / 1062860609332369$

\title{
AUTHORS AND AFFILIATIONS
}

Maryanne McGuckin, Dr. ScEd., MT(ASCP) ${ }^{1,2}$, Richard Waterman, PhD ${ }^{3,4}$, John Govednik, $\mathrm{MS}^{1,4}$

${ }^{1}$ McGuckin Methods International, Ardmore PA, ${ }^{2}$ Jefferson Medical College Department of Health Policy, Philadelphia, PA, ${ }^{3}$ University of Pennsylvania, Philadelphia, PA, ${ }^{4}$ Analytic Business Services, Huntingdon Valley, PA

\section{RUNNING TITLE}

Hand Hygiene Compliance and Measurement

\section{CORRESPONDING AUTHOR}

Dr. Maryanne McGuckin

McGuckin Methods International

115 E. Athens Avenue

Ardmore, PA 19003

Phone (610) 304-2927

Fax (610) 649-2960 
mcguckin@hhreports.com

\section{CO-AUTHORS}

Dr. Richard Waterman, richard_waterman@anabus.com

Mr. John Govednik, govednik@hhreports.com

Presented in part:

Society for Healthcare Epidemiology of American Annual Meetings, Philadelphia 2005 and Baltimore 2007, and Association for Practitioners in Infection Control Annual Meetings, Los Angeles 2005 and Tampa, 2006. 


\section{CONFLICTS OF INTEREST AND FINANCIAL DISCLOSURE}

The authors claim no financial or personal conflicts of interest. COI/Financial Disclosure form submitted to AJMQ. 


\begin{abstract}
Hand hygiene $(\mathrm{HH})$ is the single most important factor in the prevention of healthcare acquired infections (HAIs). The three most frequently reported methods of measuring $\mathrm{HH}$ compliance are (1) direct observation, (2) self-reporting by healthcare workers (HCWs), and (3) indirect calculation based on $\mathrm{HH}$ product usage.

This paper presents the results of a 12 month multicenter collaboration assessing HH compliance rates at healthcare facilities in the U.S. by measuring and providing feedback for $\mathrm{HH}$ compliance. Our results show that $\mathrm{HH}$ compliance at baseline is $26 \%$ for Intensive Care Units (ICUs), and 36\% for non-ICUs. After 12 months of measuring product usage and providing feedback, compliance increased to $37 \%$ for ICUs and $51 \%$ for non-ICUs. (ICU p=0.0119, NON-ICU p < 0.001).

HH compliance in the U.S. can increase when monitoring is combined with feedback. However, HH still occurs at or below $50 \%$ for compliance for both ICUs and non-ICUs.
\end{abstract}




\section{INTRODUCTION}

The importance of hand hygiene $(\mathrm{HH})$ in the control of infection has been recognized since the initial reports of Semmelweis in $1847 .{ }^{1}$ Several studies have shown a decrease in transmission of infection as the $\mathrm{HH}$ increases. ${ }^{2-7}$

In 2002, the Guidelines for Hand Hygiene in Health Care Facilities, ${ }^{8}$ and in 2005, the World Health Organization (WHO) Guidelines On Hand Hygiene in Health Care (advanced draft), ${ }^{9}$ presented current knowledge on hygiene products, clinical relevance, and evaluation of effective systems to promote and monitor $\mathrm{HH}$ compliance. However, measuring the impact of educational interventions that promote increased $\mathrm{HH}$ was not fully addressed by healthcare facilities until the Joint Commission (JC) released National Patient Safety Goal \#7A (2005) ${ }^{10}$ recommending the monitoring of HH compliance.

Although the Centers for Disease Control (CDC), WHO, JC, and Institute of Healthcare Improvement (IHI) all recognize the importance of monitoring $\mathrm{HH}$ compliance, there is no standard for measuring HH compliance. In 2007, Haas, et al, conducted an extensive review of the literature on $\mathrm{HH}$ monitoring, resulting in 662 articles of which only 31 described the method used to measure HH compliance. ${ }^{11}$ The reviewer identified the three most frequently reported methods of measuring compliance as (1) direct observation, (2) self-reporting of healthcare worker, and (3) indirect calculations based on hand hygiene product usage.

This paper presents the methodology and results of a one-year collaborative study of the indirect determination of $\mathrm{HH}$ compliance by measurement of product usage volume and the effect of feedback reporting on compliance. The role of measurement 
within a healthcare facility's overall program of improving $\mathrm{HH}$ using observation, education, and reporting, is discussed.

\section{METHODS}

\section{Site Enrollment}

The measurement program was offered to all healthcare facilities in United States. The only criteria for enrollment was the ability and willingness of sites to submit monthly summaries of product usage volume and patient bed days to a secure, protected database for use in generating measuring and benchmarking reports. Sites were encouraged to use reports as feedback to their HCWs. Each site received an implementation manual and support from the authors for implementing the program at their facility.

\section{Product Usage Monitoring}

Soap and sanitizer usage was monitored by collecting and counting empty (used) product containers, keeping the sum for soap separate from that of sanitizer. The sum of empty containers was either provided by a healthcare facility's environmental services or gathered by internally-assigned staff monitors who would monitor and count empty containers. The tallies of empty soap and empty sanitizer containers were recorded either separately by each unit (a specific floor or department within the facility), or, tallies for all units were combined and reported as a one facility-wide effort.

\section{Patient Bed Days or Patient Visits}

In conjunction with monitoring product usage volume, the study required Infection Control Practitioners (ICPs) to record and submit patient bed day data for each unit monitored for the study. In the case of emergency rooms or other out patient units 
such as clinics, the number of patient visits substituted for patient bed days. As with the product usage, if a facility decided to combine all units into one facility-wide monitoring effort, then patient bed days and patient visits were combined as well into one facilitywide number and submitted.

\section{Data Collection Timetable}

Product usage was monitored and reported starting at a baseline (period numbered as zero) and then monthly thereafter (periods numbered 1, 2, 3, etc). The baseline served as the starting point to which all future months' data would be compared. For each monthly period, environmental services or the staff monitors would report the total number of empty soap, empty sanitizer, and patient bed days for each unit they were

monitoring. Then, the count started over for each subsequent month. Most data was collected by on-site staff, and then submitted to the authors by a single representative from that facility, usually the ICP. Data was submitted electronically, faxed, or mailed by the $15^{\text {th }}$ of each month and reports generated and sent via e-mail (as a PDF) to each enrolled site by the $22^{\text {nd }}$ of each month. Facilities that submitted data for individual units, received reports for each unit. Facilities that submitted their data as a facility-wide sum for product usage and bed days, received one report for the entire facility.

\section{Data Analysis}

\section{Hand hygiene per patient bed day ( $\mathrm{HH} /$ patient bed day).}

$\mathrm{HH} /$ patient bed day was calculated in a multi-step process, starting by multiplying the number of used containers of soap or sanitizer by the number of milliliters for each respective product container size. Ounces were converted to milliliters if required for this step. The resulting number was the total product volume (in ML) used for that monthly 
period. That total product volume was divided by the number of patient bed days, resulting in a number that represented the total volume of product used per patient per day (also in $\mathrm{mL}$ ). Finally, that total product per patient per day was divided by $1.7 \mathrm{~mL}$ (Industry literature suggests that $1.7 \mathrm{~mL}$ is the average volume of single dose of product from a sink or freestanding product dispenser.). This final number represents the $\mathrm{HH} /$ patient bed day (for ER and other out patient units, the number represents $\mathrm{HH} /$ patient visit). This represents either the number of times $\mathrm{HH}$ occurred in a 24 hour period when there was a patient in the bed, or for out patient units, the number of times $\mathrm{HH}$ occurred per patient visit.

Statistical Methods. In order to test the statistical significance of the intervention, paired t-tests were performed on the log-transformed $\mathrm{HH}$ per patient bed day data, for the different unit types.

Benchmarks. The benchmarks are calculated using data from every unit of every healthcare facility that participated in the program. The methodology used for the benchmarking is a linear regression model, and the percentile benchmarks are drawn from the same model, using prediction intervals.

Comparative Benchmark. Benchmarks are drawn at the expected mean over all comparable units and at the 10th and 90th percentiles. The comparisons are made against similar unit types and also by hospital size classifications according to their licensed number of beds. Benchmarks are not calculated by the number of staff contacts with the patient, or by the category of staff, because these factors are determined by the type of unit. 
There are six unit types: (1) Intensive Care Unit (ICU), (2) Non-Intensive Care Unit (non-ICU), (3) Rehab / Long Term Care (rehab/LT), (4) pediatric, (5) emergency room - out patient units $(E R-O P)$, and (6) clinic.

There are four size classifications according to the number of licensed beds: (1) 1-100 beds, (2) 101-300 beds, (3) 301-500 beds, and (4) 500+ beds. This crossclassification generates twenty-four different possible reference groups that can be benchmarked. For this report, benchmarks are presented for the ICU and non-ICU categories. Data on the remaining unit types will be include the number of units and the baseline mean since there are not sufficient data points at this time to benchmark.

Compliance Goals. Table I lists the HH goals and evidence that we used to determine these goals for the six unit types. There are no compliance goals for a healthcare facility that reports their combined unit summary of product usage. Four types of research were used to determine these goals: (1) literature, (2) survey of ICPs, (M. McGuckin, unpublished data, 2006) (3) observation by ICPs, (C. Squire, VA Pittsburgh, personal communication, 2007) and (4) ongoing monitoring of the database used in this study. Any type of $\mathrm{HH}$ action that involves soap or sanitizer counts as an occurrence for HH compliance.

When an individual unit receives their $\mathrm{HH} /$ patient bed day, that number is then compared to the compliance goal. A percentage, or, compliance rate, is determined which put that unit's $\mathrm{HH} /$ patient bed day in perspective of their goal.

\section{Measurement Reports}

After an ICP submits data on soap and sanitizer product usage to our database, a report is generated which contains four graphs and one table that are used to visually 
display that month's HH/patient bed day and the compliance rate. These reports are used for feedback to HCWs and provide the ICP with a form of intervention. The graphs show where that particular unit is benchmarked with other units within that facility's size classification.

Each of the four graphs and one table are explained here:

$1 \mathrm{HH} /$ patient bed day line graph for soap for the unit for the entire time period the unit has been reporting data. This is a line graph, and each monthly intervention is represented by a point on that graph allowing easy review increases or decreases in $\mathrm{HH} /$ patient bed day over a period of several monthly interventions.

$2 \mathrm{HH} /$ patient bed day (or $\mathrm{HH} /$ patient visit) for sanitizer for the unit for the entire time period the unit has been reporting data. This is a similar type of line graph as for soap.

$3 \mathrm{HH} /$ patient bed day (or HH/patient visit for ER-OPs) for combined soap + sanitizer for the unit for the entire time period the unit has been reporting data. For this line graph, the individual $\mathrm{HH} /$ patient bed day for soap and sanitizer are combined into one number per intervention period, so that one line graph is shown for the comprehensive $\mathrm{HH}$ product use of that unit. This graph shows the compliance goal for that unit type.

\section{$4 \mathrm{HH} /$ patient bed day bar graph for soap, sanitizer, and combined} soap + sanitizer. This is the same data results as represented by each of the line graph above, only soap and sanitizer usage is represented by vertical bars instead of as points on a timeline. 


\section{$5 \mathrm{HH} /$ patient bed day for soap, sanitizer, and combined soap +} sanitizer, with compliance rate. This table documents the HH/patient bed day for each intervention period, showing individual soap and sanitizer product use, combined product use, and the compliance rate when the combined use is compared to the goal for that unit type.

\section{RESULTS}

It was decided to use the 12 month intervention as the time period at which to do the statistical analysis of the intervention because it represented a good compromise between having a sufficient sample size to obtain reasonable statistical power for the test and was far enough from the baseline in order to judge the medium-term effectiveness of the program.

Figure I shows the geographic distribution of the database used for this analysis. Healthcare facilities are shown by state and facility size classification. The database is comprised of urban and rural facilities spread across the U.S. It also has facilities represented in each size category.

In this study there were a total of 306 hospitals and other healthcare facilities submitting data for a total of 1531 units: 179 hospitals reported product use for 299 ICUs, and 281 hospitals reported product use for 986 non-ICUs. There were a combined number of 246 data points for Pediatrics, Rehab/LTC, and ER-OP.

Table II shows the mean HH/patient bed day over the period of 12 months for all ICUs and non-ICUs as well as their respective compliance rates. The compliance rate for ICUs at period 0 , the baseline, was $25.8 \%$ and increased to $36.3 \%$ by period 12 (the oneyear intervention mark, $\mathrm{p}=0.0119$ ). For Non-ICUs, the baseline was $35.7 \%$ and increased 
to $51.3 \%$ by period $12(\mathrm{p}<0.0001)$. There is not sufficient data to perform a formal test of significance for the Pediatrics, Rehab/LTC, Clinic, and ER-OP unit types. However, Table III shows the mean baseline of the limited data points we have for the HH/patient bed day for Rehab/LTC and Pediatrics to be 17.2 and $31.2 \mathrm{HH} /$ patient bed day respectively. ER/OP is 9.3HH/.patient visit and clinic is $3.7 \mathrm{HH} /$ patient visit. Based on our established compliance goals, Rehab/LTC has a mean compliance rate of $88 \%$, pediatrics $43 \%$.

Figure II shows aggregate HH/patient bed day for all 299 ICUs' combined soap and sanitizer usage. The mean $\mathrm{HH} /$ patient bed day for each intervention period is indicated by squares. Benchmarks are shown at the tenth percentile (bottom 10\%, indicated by triangles) and the $90^{\text {th }}$ percentile (top $10 \%$, indicated by diamonds). The goal for ICUs, $144 \mathrm{HH} /$ patient bed day, is indicated by the horizontal dashed line. We include an actual hospital's data from our database, to show an example of how monthly tracking would look in an actual report that goes out to an ICP. This hospital's $\mathrm{HH} /$ patient bed day are indicated by circles connected by the thick black line.

Figure III shows the aggregate $\mathrm{HH}$ /patient bed day for all non-ICUs' combined soap and sanitizer usage. Our database has a total of 986 non-ICUs. The mean $\mathrm{HH} /$ patient bed day for each intervention period is indicated by squares. Benchmarks are shown at the tenth percentile (bottom $10 \%$, indicated by triangles) and the $90^{\text {th }}$ percentile (top $10 \%$, indicated by diamonds). The goal for non-ICUs, $72 \mathrm{HH} /$ patient bed day, is indicated by the horizontal dashed line. We include an actual hospital's data from our database, to show an example of how monthly tracking would look in an actual report that goes out to an ICP. This hospital's HH/patient bed day are indicated by circles connected by the thick black line. 


\section{DISCUSSION}

There have been numerous studies over the past 25 years documenting the lack of HH compliance among HCWs. These studies have been hospital or unit specific and the majority has used either observation or HCW self-reporting on the measurements. To our knowledge this study is the first multicenter project in the U.S. designed to measure and benchmark $\mathrm{HH}$ compliance indirectly by using the measurement of product volume and cross-classification that generated twenty-four reference groups for benchmarking.

Direct observation is recognized by $\mathrm{WHO}^{9}$ as the "gold standard" and most reliable method for measuring $\mathrm{HH}$ compliance rates. Although direct observation can provide specific information about $\mathrm{HH}$ techniques and $\mathrm{HCW} \mathrm{HH}$ behavior, it is costly and labor intensive. Table IV compares labor costs for observation versus product usage measurement. Costs in terms of ICP time/salary to manage and supervise an observational study can range from 2.5 to 3.5 times as high compared to when an ICP manages a monitoring program for product usage.

The lack of standardization of a process for observation along with the bias selection and small sampling has made data hard to interpret or compare. Gould et al identified 42 techniques for measuring handwashing performance using direct

observation. ${ }^{18}$ They found poorly derived studies, limited scope in terms of time and type of units, and validity and reliability were not addressed. The author concluded that an additional data collection method should be used to address the deficiencies of observation. The most significant deficiency in observation is the small sampling size. The most comprehensive study of this issue was done by van de Mortel et al in which they reported that covert observation only captures three percent of encounters. ${ }^{19}$ 
Indirect measurements of hand hygiene such as product volume, paper towels, and containers of touch free dispensers, have reported good correlation with infection rates and resistant organisms, and increase in compliance. ${ }^{20-25}$ Product usage is a costeffective, less time-consuming method that provides the ICP with overall compliance rate for each unit, representative of all shifts, and avoids biases of selection and self-reporting.

The methodology for product usage measurement does not produce data for $\mathrm{HH}$ techniques, nor does it provide indications in terms of before and after patient contact. For these reasons, product usage measurement can be used as a cost effective way to determine which units one should perform observation to better understand non compliance $\mathrm{HH}$ behaviors for a specific unit.

Research studies have shown that a sound component of a compliance program is reporting and feedback. Rosenthal et al reported a significant increase in $\mathrm{HH}$ compliance when performance feedback was introduced. ${ }^{26}$ Similar results were reported by McCormick et al on the use of unit specific report cards. The discussion (and promotion) of HH goals, and the unit's compliance towards those goals, provided motivation to increase instances in $\mathrm{HH}^{27}$ The measurement and benchmarking reports, whose data is impacted by the educational efforts of a facility's $\mathrm{HH}$ awareness, were used in turn to influence that educational program. The reports were used in monthly infection control committee meetings, unit staff meetings, and training sessions, to provide feedback for that unit's $\mathrm{HH}$ behavior.

Standardization of $\mathrm{HH}$ measurement should be the foundation of a compliance program, and the process of applying a standard methodology will increase the probability of improving $\mathrm{HH}$ compliance. The $\mathrm{HH}$ compliance measurement process used in our multicentered program uses a standard methodology for all units at all 
facilities, and provides a standard reporting method that can be used for feedback and benchmarking. It provides a method for monitoring and unit-specific feedback, both of which have been shown to increase and sustain hand hygiene compliance. ${ }^{21-25}$

The compliance rates from this study represent the first attempt to look at monitoring across the U.S. using a standard collection method, data analysis, and benchmarking based on compliance goals. These results are the first to differentiate between ICUs and non-ICUs, and the first to quantify compliance for both types of units.

The aggregate results show that in the ICU, the mean $\mathrm{HH} /$ patient bed day when sites begin their monitoring is $37 \mathrm{HH} /$ patient bed day, meaning $\mathrm{HH}$ occurred on average 37 times in a 24 hour period when there was patient in the bed. Based on our established goals, there should be approximately $144 \mathrm{HH}$ in a 24 hour period when there is a patient in an ICU bed. Therefore, the compliance rate for ICUs is $25 \%$. At 12 months $\mathrm{HH} /$ patient bed day increased to $52 \mathrm{HH} /$ patient bed day, representing a compliance rate of $36 \%$.

For the non-ICUs, the mean $\mathrm{HH} /$ patient bed day is $26 \mathrm{HH} /$ patient bed day. The established goal is $72 \mathrm{HH} /$ patient bed day. This is a $36 \%$ compliance rate. At 12 months, non-ICUs increase to $37 \mathrm{HH} /$ patient bed day, resulting in a $51 \%$ compliance rate. Our data has also shown that Pediatrics has a higher mean compliance goal than ICU and Non-ICU, a fact that has been shown in previous studies on HH in Pediatrics. ${ }^{17,28-29}$ National multicenter studies on hand hygiene have been performed in Southern Mediterranean countries and in Turkey. Arikan Akan, et al, in a national multicenter study in Turkey, reported similarly low compliance rates of $29.8 \% \mathrm{HH}_{\text {for ICUs. }}{ }^{30}$ Amazian, et al, reported as part of the NosoMed Network, HH compliance rates in four 
Southern Mediterranean countries. They found similarly low compliance rates of $27.6 \%$ overall, with lack of consumables a significant factor. ${ }^{31}$

The limitations of this study are related to product monitoring and compliance goals. Although we have standardized the process for collecting and submitting product volume (collecting the empty containers), it still remains a manual process and therefore human error can occur. The effect of human error on a specific site is not critical since each site is monitored and compared to their baseline data. Consistency is the key even if there are a few minor flaws. We have found that the process of establishing a baseline and first month's intervention requires each site to begin each of these periods by replacing all soap and sanitizer containers in each unit of their study, so that product use can be measured more precisely. If there is a significant error in measurement in the months following the baseline and first month, it is more obvious when compared to the earlier interventions and we can help that facility's ICP identify where the error in measurement occurred. Our compliance goals were based on published articles which described a total of several thousand observation hours. The goals also are based on ongoing observation as sites participated in this study. Our goals may be too low due to the reported lack of standardization of observation and the reported low yield using this process. We believe this is the case for the Rehab/LTC, ER/Op and /Clinic goals we have noted because of the variability in defining these units and the difference in the acuity of patients. However, even with possible low goals, compliance for ICUs and Non-ICUs is still near or below $50 \%$ in this multicenter study.

Our findings have documented three important facts: (1) monitoring and feedback can result in a modest but statistically significant increase in $\mathrm{HH}$ compliance, (2) $\mathrm{HH}$ in the U.S. continues to be near or below $50 \%$ with compliance slightly higher for 
non-ICUs than for ICUs, and (3) monitoring compliance through product volume is a time efficient, cost effective way to provide feedback to staff and provide direction for observation and education. 


\section{References:}

1. Semmelwies I, Carter K. Etiology, Concept, and Prophylaxis of Childbed Fever. Madison, WI: University of Wisconsin Press; 1983.

2. Pittet D. Compliance with hand disinfection and its impact on hospital-acquired infections. J Hosp Infect. 2001;48:540-546.

3. Rosenthal VD, Guzman S, Safdar N. Reduction in nosocomial infection with improved hand hygiene in intensive care units of a tertiary care hospital in Argentina. Am J Infect Control. 2005;33:392-397.

4. Won S, Chou H, Hsieh W, et al. Handwashing program for the prevention of nosocomial infections in a neonatal intensive care unit. Infect Control Hosp Epidemiol. 2001;25:742-746.

5. Aiello A, Larson E. What is the evidence for a causal link between hygiene and infections? Lancet Infect Dis. 2002;2:103-110.

6. Pittet D, Hugonnet S, Harbarth S, et al. Effectiveness of a hospital-wide programme to improve compliance with hand hygiene. Lancet 2000;356:1307-1312.

7. Aragon D, Sole ML, Brown S. Outcomes of an infection prevention project focusing on hand hygiene and isolation practices. AACN Clin Issues 2005;16:121-132. 
8. Boyce JM, Pittet D. Guideline for hand hygiene in healthcare settings. Morbid Mortal Weekly Rev 2002;51(RR1):1-44.

9. World Alliance for Patient Safety. WHO guidelines on hand hygiene in health care (advanced draft). April 2006.

10. Joint Commission of Accreditation of Healthcare Organizations. Patient Safety Goals [on the internet]. The Joint Commission web site. http://www.jcaho.org/accredited+organizations/patient+safety/npsg.htm. Accessed December 20, 2005.

11. Haas J.P, Larson E.L. Measurement of compliance with hand hygiene. J Hosp Infect. 2007;66:6-14.

12. Rumbara R. A point-in-time observational study of hand washing practices of healthcare workers in the intensive care unit of St. Luke's Medical Center [on the internet]. Philippine Journal of Microbiology and Infections Diseases. 2001;30(1): http://www.psmid.org.ph/vol30/vol30num1 topic2.pdf. Accessed February 27, 2008

13. Swaboda SM, Earsing K, Strauss K, Lane S, Lipsett PA. Electronic monitoring and voice prompts improve hand hygiene and decrease nosocomial infections in an intermediate care unit. Crit Care Med. 2004;32(2):358-363. 
14. McArdle MI, Lee RJ, Gibb AP, Walsh TS. How much time is needed for hand hygiene in intensive care? A prospective trained observer study of rates of contact between healthcare workers and intensive care patients. J Hosp Infect. 2006;62:304310.

15. Rabaud J, Saskin R, Wong K, et al. Patterns of handwashing behavior and visits to patients on a general medical ward of healthcare workers. Infect Control Hosp Epidemiol. March 2004;25(3): www.ichejournal.com/showAbst.asp?thing=7670. Accessed February 25, 2005.

16. Walanakunakorn C, Wang C, Hazy J. An observational study of hand washing and infection control practices by healthcare workers [on the internet]. PubMed web site. www.pubmed.gov PMID 9832945. Accessed Aug. 8, 2007.

17. Larson EL, Albrecht S, O'Keefe M. Hand hygiene behavior in a pediatric emergency department and a pediatric intensive care unit; comparison of use of 2 dispenser systems. Am J Crit Care 2005;14:304-310.

18. Gould DJ, Chudleigh J, Drey NS, Moralejo D. Measuring handwashing performance in health service audits and research studies. J Hosp Infect. 2007;66:109-115.

19. van de Mortel T, Murgo M. An examination of covert observation and solution audit as tools to measure the success of hand hygiene interventions. Am J Infect Control 2006;34:95-99. 
20. Bittner MJ, Rich EC. Surveillance of handwashing episodes in adult intensive-care units by measuring an index of soap and paper towel consumption. Clin Perform Qual Health Care 1998;6:179-182.

21. McGuckin M, Waterman R, Porten L, et al. Patient education model for increasing handwashing compliance. Am J Infect Control 1999;27:309-14.

22. McGuckin M, Waterman R, Storr J, et al. Evaluation of a patient-empowering hand hygiene programme in the UK. J Hosp Infect 2001;48:222-227.

23. McGuckin M, Taylor A, Martin V, Porten L, Salcido R. Evaluation of a patient education model for increasing hand hygiene compliance in an inpatient rehabilitation unit. Am J Infect Control 2004;32:235-238.

24. McGuckin M, Porten L, Schmidt R, Streed S. Validation of a comprehensive infection control program in LTC. The Director 2004;12(1):14-17.

25. McGuckin M, Shubin A, McBride P, et al. The effect of random voice hand hygiene messages delivered by medical, nursing, and infection control staff on hand hygiene compliance in intensive care. Am J Infect Control.2006;34(10):673-675. 
26. Rosenthal VD, McCormick RD, Guzman S, Villamayor C, Orellano PW. Effect of education and performance feedback on handwashing: the benefit of administrative support in Argentinean hospitals. AM J Infect Control. 2003;31:85-92.

27. McCormick, et al. The impact of feedback to healthcare workers using a monthly report and on hand hygiene compliance. Abstract presented at: Annual meeting of the Society for Healthcare Epidemiology of America;2007;Baltimore, MD.

28. Harbarth S, Pittet D, Grady L, Goldmann DA. Compliance with hand hygiene practice in pediatric intensive care: Clinical Investigations. Pediatr Crit Care Med. $2001 ; 2(4): 311-314$.

29. Howell K, Kieffer P, Perulfi S. Give hygiene a hand at the hospital. [on the internet] St. Louis Children's Hospital web site. http://www.stlouischildrens.org/tabid/159/itemid/3793/Give-Hygiene-a-Hand-at-theHospital.aspx Accessed March 18, 2008.

30. Arikan Akan Q, Cetinkaya Y, Ozgultekin A, et al. National multi-center study to evaluate the baseline handwashing compliance in the intensive care units of three Turkish hospitals : differences between genders. Am J Infect Control. 2004;32(3):E57-E58. 
31. Amazian K, Abdelmoumene T, Sekkat S, et al. Multicentre study on hand hygiene facilities and practice in the Mediterranean area: results from the NosoMed Network. J Hosp Infect. 2006;62(3):311-318. 


\section{Table I: Compliance Goals for Each Unit Type}

\begin{tabular}{|c|c|c|c|}
\hline $\begin{array}{l}\text { Unit } \\
\text { Type }\end{array}$ & $\begin{array}{c}\text { Compliance Goal } \\
\mathrm{HH} / \text { patient bed day } \\
\text { or } \mathrm{HH} / \text { patient visit }\end{array}$ & $\begin{array}{l}\text { Research } \\
\text { Evidence }\end{array}$ & Reference \\
\hline \multirow[b]{3}{*}{ ICU } & \multirow[b]{3}{*}{144} & $9 \mathrm{HH} /$ hour & Rumbara et al ${ }^{12}$ \\
\hline & & $4 \mathrm{HH} /$ hour & Swaboda et $\mathrm{al}^{13}$ \\
\hline & & $158 \mathrm{HH} /$ day & McArdle et $\mathrm{al}^{14}$ \\
\hline \multirow[b]{2}{*}{ NON-ICU } & \multirow[b]{2}{*}{72} & $1 \mathrm{HH} / 25 \mathrm{~min}$ & 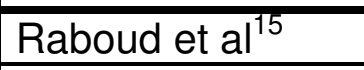 \\
\hline & & $\begin{array}{l}\text { NON-ICU should } \\
\text { be half ICU }\end{array}$ & Walanakunakorn $^{16}$ \\
\hline REHAB/LT & 20 & $20 \mathrm{HH} / \mathrm{bd}$ & Squire \\
\hline PEDIATRICS & 72 & $\begin{array}{l}4.89 \mathrm{HH} / \text { hour (pre } \\
\text { contact) } \\
3.65 \mathrm{HH} / \text { hour } \\
\text { (post contact) }\end{array}$ & Larson et al ${ }^{17}$ \\
\hline ER-OP & 6 & $6 \mathrm{HH} / \mathrm{pv}$ & MMI \\
\hline CLINIC & 3 & $3 \mathrm{HH} / \mathrm{pv}$ & $\mathrm{MMI}$ \\
\hline
\end{tabular}

Sources used to establish compliance goals for $\mathrm{HH} /$ patient bed day or $\mathrm{HH} /$ patient visit for each of the six unit types. Compliance goals are the standard to which individual units in the program compare their monthly reports. 


\section{Figure I: Product Volume Measurement in the U.S.}

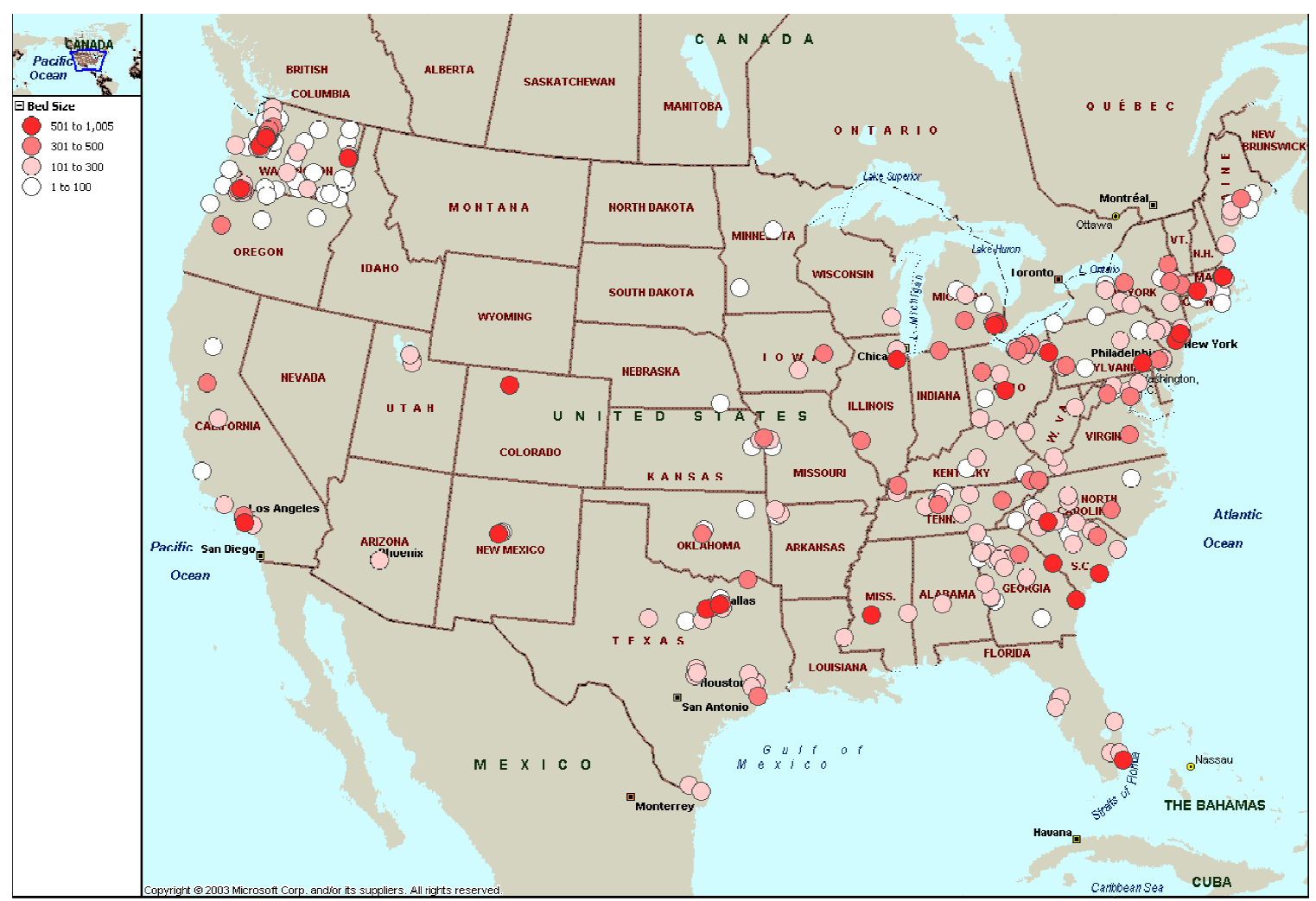

Map of U.S. showing locations of hospitals and other healthcare facilities that have used product usage measurement to determine their hand hygiene compliance rate. There are 306 healthcare facilities in the following size classes: $1-100$ beds (98 sites shown as white circles), 101-300 beds (130 sites, shown as light-shade circles), 301-500 beds (49 sites, shown as dark-shade circles), 501 beds and greater ( 29 sites shown as dark circles). 


\section{Table II: ICU and non-ICU HH/patient bed day Means and Compliance Rates}

\begin{tabular}{|c|c|c|c|c|}
\hline $\begin{array}{c}\text { Data Collection } \\
\text { Period (month) }\end{array}$ & $\begin{array}{c}\text { ICU } \\
\text { HH/patient bed } \\
\text { day mean }\end{array}$ & $\begin{array}{c}\text { ICU Compliance } \\
\text { Rate }\end{array}$ & $\begin{array}{c}\text { Non-ICU } \\
\text { HH/patient bed } \\
\text { day mean }\end{array}$ & $\begin{array}{c}\text { Non-ICU } \\
\text { Compliance } \\
\text { Rate }\end{array}$ \\
\hline & Goal: $\mathbf{1 4 4}$ & & Goal: $\mathbf{7 2}$ & \\
\hline $\mathbf{0}$ & 37.1 & $25.8 \%$ & 25.7 & $35.7 \%$ \\
\hline $\mathbf{1}$ & 42.1 & $29.2 \%$ & 25.6 & $35.5 \%$ \\
\hline $\mathbf{2}$ & 41.3 & $28.6 \%$ & 27.8 & $38.5 \%$ \\
\hline $\mathbf{3}$ & 44.8 & $31.1 \%$ & 27.8 & $38.5 \%$ \\
\hline $\mathbf{4}$ & 52.6 & $36.5 \%$ & 31.3 & $43.5 \%$ \\
\hline $\mathbf{5}$ & 53.2 & $36.9 \%$ & 33.4 & $46.4 \%$ \\
\hline $\mathbf{6}$ & 50.9 & $35.3 \%$ & 32.7 & $45.4 \%$ \\
\hline $\mathbf{7}$ & 56.7 & $39.4 \%$ & 35.2 & $48.9 \%$ \\
\hline $\mathbf{8}$ & 59.5 & $41.3 \%$ & 35.2 & $48.8 \%$ \\
\hline $\mathbf{9}$ & 49.6 & $34.5 \%$ & 34.3 & $47.7 \%$ \\
\hline $\mathbf{1 0}$ & 56.1 & $38.9 \%$ & 33.7 & $46.9 \%$ \\
\hline $\mathbf{1 1}$ & 56.0 & $38.9 \%$ & 34.3 & $47.6 \%$ \\
\hline $\mathbf{1 2}$ & 52.3 & $36.3 \%$ & 37.0 & $51.3 \%$ \\
\hline
\end{tabular}

Baseline (period zero) and twelve months (one year) of product volume measurement and feedback reporting, showing monthly $\mathrm{HH} /$ patient bed days and comparing each month's $\mathrm{HH}$ /patient bed day to the compliance goals in order to determine the compliance rate. 
Table III: Rehabilitation/Long Term, Pediatrics, ER/Out Patient, Clinics $\mathrm{HH} /$ patient bed day or $\mathrm{HH} /$ patient visit Baseline Means

\begin{tabular}{|l|c|c|}
\hline \multicolumn{1}{|c|}{$\begin{array}{c}\text { Unit } \\
\text { Type }\end{array}$} & $\begin{array}{c}\text { Number of } \\
\text { Units in } \\
\text { Program }\end{array}$ & $\begin{array}{c}\text { Baseline } \\
\text { Mean }\end{array}$ \\
\hline Rehab/LT & 49 & 17.2 \\
\hline Pediatrics & 51 & 31.9 \\
\hline ER/OP & 104 & 9.3 \\
\hline Clinic & 42 & 3.7 \\
\hline
\end{tabular}

Baseline (period zero) mean for Rehabilitation, Long Term Care and Pediatric (reported as HH/per patient bed day) and mean for Emergency room, Outpatients clinics such as Vascular Lab. and Clinics such as Dermatology (reported as $\mathrm{HH} /$ per patient visit. 
Figure II: Aggregate Data for ICUs in Database and Example of a Single ICU Benchmarking

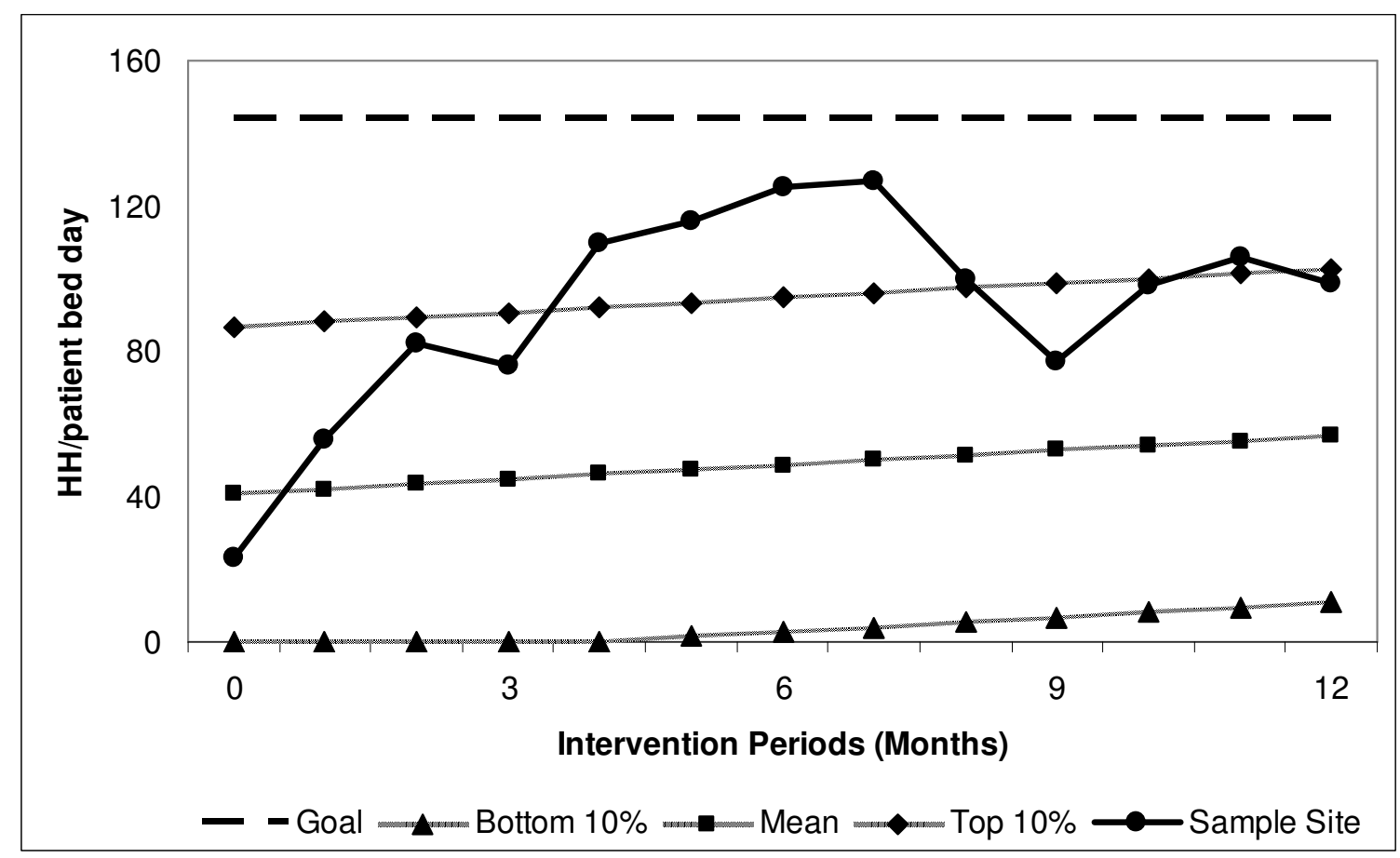

An example ICU from the database showing combined soap + sanitizer usage over a 12 month period. Also shown are the compliance goal $(144 \mathrm{HH} /$ patient bed day), mean, and benchmarks for the $10^{\text {th }}$ percentile (bottom $10 \%$ ), and $90^{\text {th }}$ percentile (top 10\%) for all hospitals in the same size class. 
Figure III: Aggregate Data for NON- ICUs in Database and Example of Single Non-ICU Benchmarking

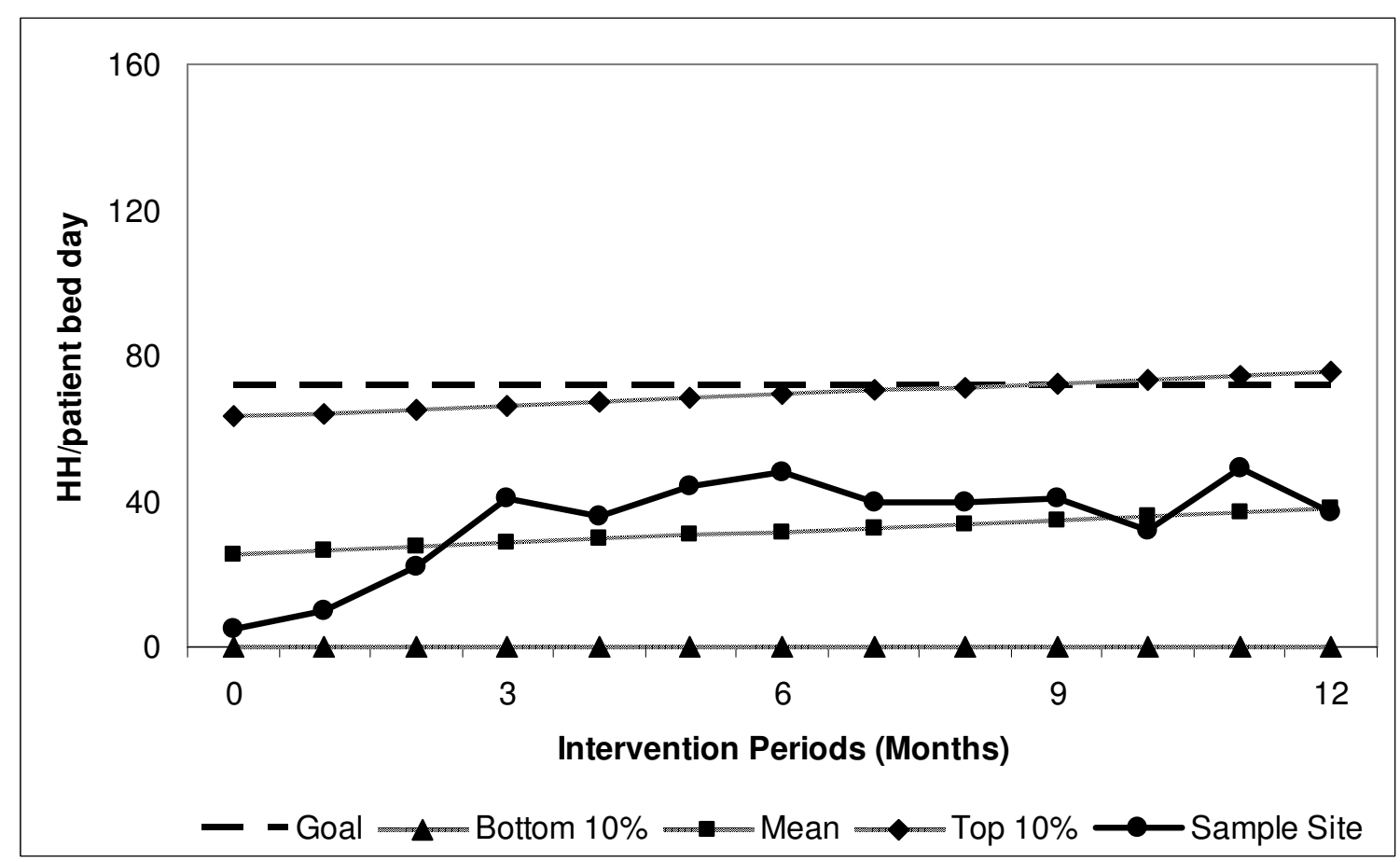

An example non-ICU from the database showing combined soap + sanitizer usage over a 12 month period. Also shown are the compliance goal $\left(72 \mathrm{HH} /\right.$ patient bed day), mean, and benchmarks for the $10^{\text {th }}$ percentile (bottom $10 \%$ ), and $90^{\text {th }}$ percentile (top 10\%) for hospitals in the same size class. 
Table IV: Annual Personnel Costs for Observational Studies versus Product Usage Measurement

\begin{tabular}{|c|r|r|r|}
\hline & \multicolumn{2}{|c|}{ Observation } & $\begin{array}{c}\text { Product Volume } \\
\text { Measurement }\end{array}$ \\
\hline Number of Units & By ICP $^{*}$ & $\begin{array}{c}\text { By Non- } \\
\text { Professional }^{* *}\end{array}$ & By Team $^{* \star *}$ \\
\hline 4 & $\$ 6,656$ & $\$ 3,456$ & $\$ 2,596$ \\
\hline 8 & $\$ 13,312$ & $\$ 5,376$ & $\$ 4,596$ \\
\hline 12 & $\$ 19,968$ & $\$ 7,296$ & $\$ 6,296$ \\
\hline 22 & $\$ 36,608$ & $\$ 12,096$ & $\$ 10,496$ \\
\hline
\end{tabular}

*ICP median base salary in U.S. is $\$ 32 /$ hour (not incl. benefits). Figures in ICP column based on ICP performing observation one hour per unit per week. No reports or benchmarking

${ }^{* *}$ Data Collector base salary in U.S. is $\$ 10 /$ hour. Figures in Non-Professional column based on a data collector observing one hour per unit per week, and includes ICP supervision time/cost. No report or benchmarking

${ }^{* *}$ Team cost are for ICP Monthly time for overseeing program, and fee for measurement and benchmarking reports. Includes report and benchmarking 


\section{REPRINT REQUESTS}

McGuckin Methods International

115 E. Athens Avenue

Ardmore, PA 19003

Phone (610) 304-2927

Fax (610) 649-2960

mcguckin@hhreports.com 